\title{
Using the Elaboration Likelihood Model to Explain Performance Appraisal Inaccuracies
}

\author{
Don A. Larsen \\ Montana State University Billings
}

Performance appraisal inaccuracy has received research attention partly due to actual job performance explaining a small portion of rating variance. This paper uses the Elaboration Likelihood Model (ELM) to explain how and when factors unrelated to job performance will influence the performance evaluation process due to a rater's lack of ability or motivation. Potential variables affecting rater motivation and ability to accurately assess employee performance are explained via the ELM, and several factors shown in previous research to affect rater accuracy are explained via the ELM framework. Suggestions for future research examining performance appraisal accuracy via the ELM are provided.

Keywords: Elaboration Likelihood Model, Performance Management, Performance Appraisal Accuracy

\section{INTRODUCTION}

Performance appraisals, part of the overall performance management process, are formal evaluations that typically occur no more than one or twice a year in which employee performance is rated along specific job dimensions with the intent to provide feedback (e.g., strengths and weaknesses in performance) and to create a performance record that assists with administrative decisions and issues (e.g., promotions, pay increases, rewards, firings, legal challenges, etc.) (DeNisi \& Murphy, 2017; Dorsey $\&$ Mueller-Hanson, 2017). The accuracy of these performance evaluations has been a focus of research for decades (DeNisi \& Pritchard, 2006). Yet, a common complaint among top managers is that they hesitate to use official employee performance ratings for personnel decisions because they believe the ratings do not accurately reflect actual performance (Dorsey \& Mueller-Hanson, 2017). Employees likewise distrust performance ratings. Employees believe the ratings are not indicative of their efforts and accomplishments (Murphy \& Deckert, 2013), with one survey finding only 10\% of employees trust that their performance appraisal system provides them with useful information to improve their performance (Pulakos, 2004). These inaccuracies are one of the reasons why the performance management process has been called the "Achilles' heel" of employee workforce management (Pulakos, Mueller-Hanson, O'Leary, \& Meyrowitz, 2012), and improving ratings accuracy has been the focus of much research on performance evaluations over several decades (Brown, O'Kane, Mazumdar, \& McCracken, 2019; Kane, Bernardin, \& Wiatrowski, 1995).

Inaccuracies may be either intentional or unintentional in nature (Kane et al., 1995). Regarding intentional inaccuracies, some raters may avoid accurate ratings due to organizational politics (i.e., to achieve the desired results for a particular individual or group) or to enhance self-image (Dello Russo, 
Miraglia, \& Borgogni, 2017; Spence \& Keeping, 2011). Others may rate leniently due to little trust in the organization's ability to fairly use the performance data (Bernardin, Orban, \& Carlyle, 1981) or to avoid negative repercussions with subordinates (Longenecker, Sims, \& Gioia, 1987; Spence \& Keeping, 2011). This paper focuses on unintentional inaccuracies, the kind that occur when a rater attempts to evaluate performance accurately but is influenced by factors other than performance information. In order to improve the performance evaluation process, it is important to understand how factors unrelated to job performance can affect the decisions of raters.

The Elaboration Likelihood Model (ELM), conceived by Petty and Cacioppo (1986) to explain the process of attitude formation based on ability and motivation factors, holds promise as an explanatory framework for how and when factors unrelated to job performance will influence the performance evaluation process due to the rater's lack of ability or motivation. Consequently, this paper is organized into four sections to explain the applicability of the ELM to the performance rating process. The first section contains a brief description of the ELM and its implications on the accuracy of the performance appraisal process. Since the ELM proposes that ability and motivation are key forces in the evaluation process, the second section provides examples of several variables that may impact the ability and motivation of the rater and thus influence the degree to which the dimensions of actual job performance are scrutinized. The third section discusses, in context of the ELM, some variables known to affect performance ratings despite being unrelated to actual performance. The final section provides suggestions for utilizing the ELM in research on rater accuracy.

\section{ELM OVERVIEW AND APPLICABILITY TO PERFORMANCE EVALUATION}

A major focus of research on the performance appraisal process has been rating accuracy. From the 1940 s to the 1990 s, the focus of much of the research was on making ratings more accurate by improving rating scale design, increasing interrater agreement, and reducing rating errors and biases (DeNisi \& Pritchard, 2006; DeNisi \& Murphy, 2017; Murphy \& Cleveland, 1995). In the 1980s and 90s, research into other areas, such as the effectiveness of multiple raters (e.g., 360 degree appraisals and balanced scorecard) and the cognitive process involved in evaluating performance received an emphasis and took some focus away from appraisal accuracy (DeNisi \& Pritchard, 2006; Ilgen, Barnes-Farrell, \& McKellin, 1993).

Currently, performance appraisal research is focused on issues like contextual factors (e.g., organizational culture dimension, union vs. nonunion settings, private vs. public sector organizations, team situations, organizational goals, etc.) and their effect on variables other than accuracy in the appraisal process, such as employee reactions to and perceptions of fairness with the appraisal process (Brown et al., 2019; DeNisi \& Pritchard, 2006; Pichler, 2012). However, a fresh look at performance appraisal cognitive processes and accuracy through the perspective of the ELM might yield productive results by helping to explain circumstances that would increase the likelihood of inaccurate performance ratings. Consequently, this paper will examine relevant research, some decades old, in laying out the applicability of the ELM to performance appraisal process.

The ELM describes how an attitude is formed via persuasive arguments. According to Petty and Cacioppo (1986), an attitude is a "general evaluation people hold in regard to themselves, other people, objects, and issues" (p. 127). Since a performance appraisal is an evaluation of an individual's performance in work-related tasks, the ELM can be useful in understanding the dynamics of the ratings process. Furthermore, DeNisi and Pritchard (2006) explain that effective performance appraisal systems exist when "raters have the ability to measure employee performance and the motivation to assign the most accurate ratings" (p. 254). The ELM specifies that both ability and motivation are factors determining whether or not relevant information is considered when the evaluation is formed. Consequently, the ELM holds promise as a means to help explain when either performance-related or nonperformance-related information will affect performance ratings depending on rater ability and motivation. 
The ELM specifies that the above-mentioned evaluation takes place along a continuum of elaboration. According to Petty and Cacioppo (1986), elaboration is "the extent to which a person thinks about the issue-relevant arguments contained in a message" (p. 128). At one end of the continuum is high elaboration (i.e., central route of processing) where favorable or unfavorable evaluations are based on the strength of issue-relevant information (e.g., actual performance-related evidence) rather than peripheral cues (e.g., age, similarity, etc.). High elaboration (i.e., central processing) occurs only when both ability and motivation are high to evaluate the evidence for or against an issue (Petty \& Cacioppo, 1986). At the other end of the continuum is low elaboration (i.e., peripheral route of processing) where favorable or unfavorable evaluations are based on the positive or negative nature of peripheral cues such as source factors (e.g., credibility, attractiveness, etc.) and message factors (e.g., number of points argued, length of arguments, etc.) rather than the quality of the issue-relevant evidence. The ELM proposes that if either ability or motivation is low to assess the strength of the information provided, low elaboration (i.e., peripheral processing) occurs (Petty \& Cacioppo, 1986).

A key finding in studies using the ELM framework is an interaction resulting from the degree of elaboration employed (Petty \& Cacioppo, 1986). For individuals using high elaboration, strong issuerelated evidence is evaluated more favorably than weak evidence while peripheral cues have little bearing on the evaluation. Conversely, for individuals engaged in low elaboration, positive peripheral cues elicit a more favorable evaluation than negative peripheral cues while the strength of the issue-related evidence has little effect on the evaluation.

What are the implications of the level of elaboration on errors in the performance evaluation process? This paper proposes that unintentional inaccuracies in ratings are more likely to occur when raters engage in low elaboration as opposed to high elaboration. To evaluate performance accurately, a rater must scrutinize information relevant to performance. Whether high or low elaboration occurs in the rating process depends on the extent to which raters are both motivated and able to evaluate relevant information about employees' performance. If ability and motivation are high, raters employ high elaboration and evaluations are more likely to be formed using issue-relevant information. If either ability and/or motivation are low, raters utilize low elaboration and evaluation is influenced by peripheral cues (e.g., similarity, attractiveness, etc.). In such a case, unintentional inaccuracies in rating can surface (e.g., similarity bias, contrast effects, etc.). Consequently, raters who engage in high elaboration should rate performance more accurately and experience less unintentional rating inaccuracies than raters who engage in low elaboration.

Proposition 1: Rater elaboration will be positively correlated with accuracy of performance appraisals.

The relationships of ability and motivation, extent of elaboration, and rating inaccuracies in the context of the ELM are depicted in Figure 1. As shown in Figure 1, extent of elaboration is proposed as an antecedent of rating accuracy. The next sections discuss rater ability and motivation as antecedents of the elaboration employed. 
FIGURE 1

PERFORMANCE APPRAISAL INACCURACY IN THE CONTEXT OF THE ELM

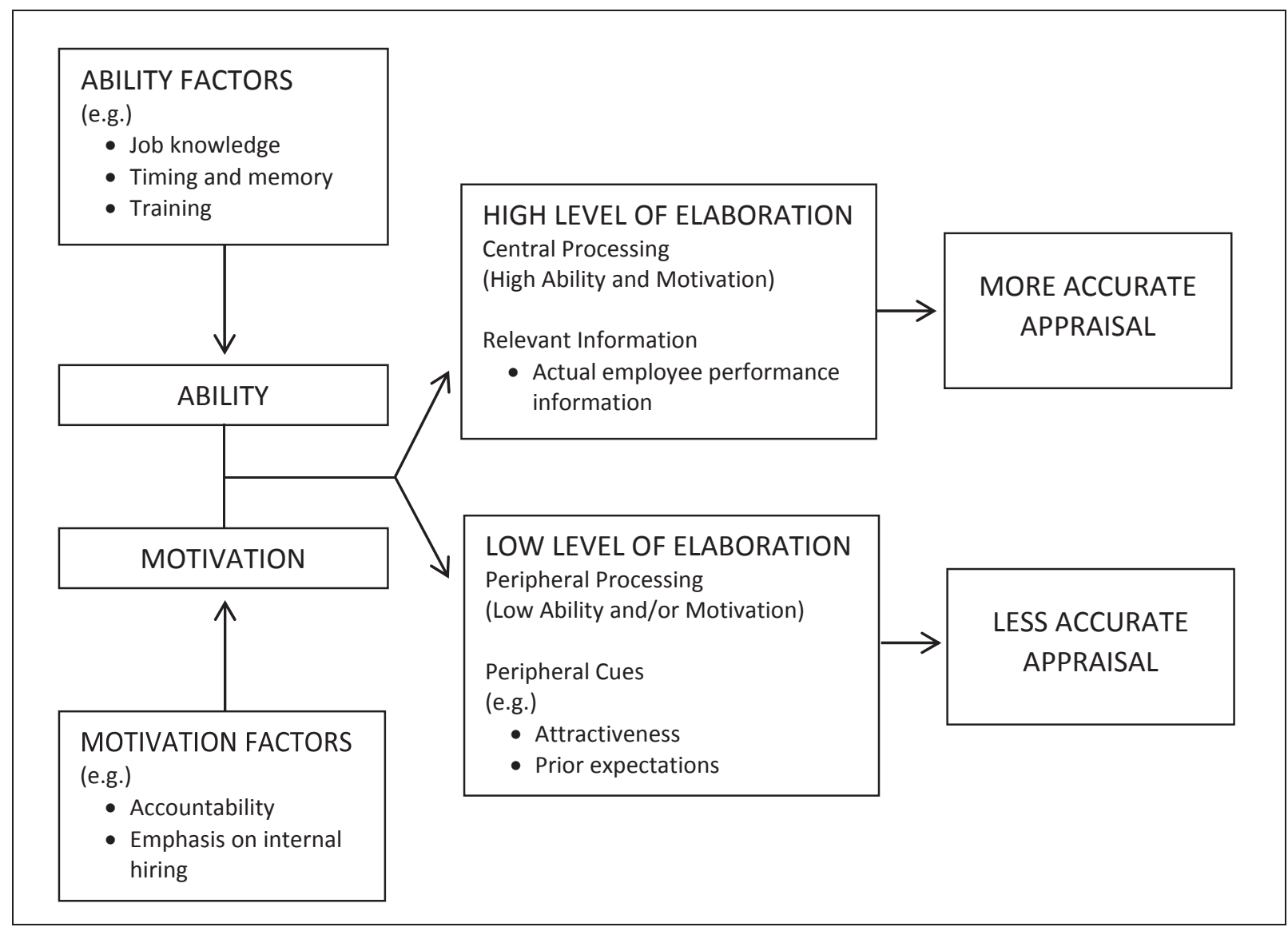

\section{ABILITY FACTORS}

When ability to rate accurately is low, raters should engage in low elaboration (i.e., peripheral processing) and be less likely than those using higher levels of elaboration to thoroughly examine relevant information concerning performance. Peripheral cues should be more likely to affect raters with low ability, resulting in inaccurate judgments. Conversely, when elaboration is high (i.e., central processing), raters should scrutinize performance-relevant information more closely, leading to more accurate appraisals.

While other factors may influence the ability of raters to accurately evaluate employee performance, the variables of job knowledge, timing or memory, and training are used to illustrate the proposed effect of rater ability on level of elaboration and ultimately rater accuracy.

\section{Job Knowledge}

The ability of a rater to accurately appraise performance depends to some degree on what the rater knows about the task the employee is performing. Often, a manager's ability to rate must overcome the challenge of having limited opportunities to actually observe subordinates performing their jobs (Brown et al., 2019). In addition, factors such as teamwork, employee autonomy, and self-managed work teams may limit management's knowledge of what an individual worker does, making it difficult to separate out individual performance. To some extent, performance review systems are built on faulty assumptions that managers who supervise employees will be around for 12 months to provide the review, and that the 
manager knows as much as the employee about what the employee's job entails and the skills and abilities needed to be successful (Goldberg, 2014).

Several studies indicate that job knowledge affects ability to rate accurately. One study found that ratings are less accurate when supervisor's observations are based on limited knowledge of the job (Heneman \& Wexley, 1983). Other findings suggest that prior knowledge of the employee's tasks is important to the accuracy of performance appraisals (Foti \& Lord, 1987). Also, Kozlowski, Kirsch, and Chao (1986) suggest that a rater's job knowledge has significant effects on rating covariance and halo error. Such research provides support for the notion that lowering a rater's ability via limited job knowledge may cause lower elaboration, resulting in an increased focus on peripheral cues in the ratings process and lower performance evaluation accuracy.

Proposition 2: Raters with low levels of job knowledge will engage in lower elaboration than raters with high levels of job knowledge, and thus are more likely to be influenced by peripheral cues in the ratings process and experience lower accuracy.

\section{Timing and Memory}

Timing and memory may also impact the ability of raters to accurately judge performance. The time at which a rater observes an individual's performance, the ordering of good and bad performance, and the effects of memory decay will alter the ability of raters to rate accurately (Sanchez \& De La Torre, 1996). Research on timing and memory has consistently shown effects on the relationship of actual performance to ratings (Arvey \& Murphy, 1998). Frank-Major and Foti (1985) suggest raters are unable to recall accurately and large halo effects are prevalent. The timing of the observations of good and poor performance seems to affect ratings, with results showing that recent poor performance is given more weight in evaluations than more distant performance (Steiner \& Rain, 1989).

Memory decay has been suggested as a factor that causes halo error and affects ability to remember job information and employee performance (Kozlowski \& Kirsch, 1987). In one study, memory decay was present only one day after the performance appraisal (Murphy \& Balzer, 1986). Efforts to overcome this deficiency through structured diary-keeping and recall methods appear to increase the rater's ability to remember and process performance-relevant information (DeNisi \& Peters, 1996).

These results indicate that the timing of the performance evaluation in relation to specific job performance activities and memory decay affect a rater's ability to assess performance accurately. In such cases, it seems more likely that a rater will engage in lower elaboration and be influenced by peripheral cues in the ratings process resulting in lower evaluation accuracy.

Proposition 3: Raters experiencing timing effects and memory decay will engage in lower elaboration than raters not experiencing such effects, and thus are more likely to be influenced by peripheral cues in the ratings process and experience lower accuracy.

\section{Training}

The final proposed variable to affect ability to accurately evaluate performance is rater training. Roch, Woehr, Mishra, and Kieszczynska (2012) state that rater training is designed to "align raters with respect to a common set of evaluative standards" (p 373), and that this is necessary since ratings are often compared between raters for administrative purposes (e.g., raises, promotions, etc.). Training typically comes in the form of helping raters increase accuracy by providing examples of behavior standards for various rating dimensions (e.g., poor, average, and good) as well as instructing how to accurately record performance data to help with recall. Wood and Marshall (2008) found that raters who receive training have higher self-efficacy in their ability to successfully complete a performance appraisal that is fair and accurate. Reviews of previous academic research (Brown et al., 2019; Roch et al., 2012; Woehr \& Huffcutt, 1994) as well as assessments of practitioners (Biron, Farndale, \& Paauwe, 2011) provide evidence that various forms of rater training can improve performance rating accuracy. In particular, frame-of-reference training, where raters are given criteria important for a job and trained to distinguish 
good to poor performance based on a performance standard, has shown improvements in performance ratings accuracy (Gorman \& Rentsch, 2009; Moser, Kemter, Wachsmann, Köver, \& Soucek, 2018; Roch et al., 2012; Woehr \& Huffcutt, 1994).

Applying the ELM framework, it appears that the knowledge gained from rater training should result in raters being able to better focus on performance-related information and the ability to distinguish among various levels of performance, thus paying less attention to peripheral cues. Untrained raters should be more likely to rely on peripheral cues and engage in lower levels of elaboration than raters who receive training, thus resulting in accuracy errors.

Proposition 4: Raters who receive no training on conducting performance appraisals will engage in lower elaboration than raters who receive training, and thus are more likely to be influenced by peripheral cues in the ratings process and experience lower accuracy.

While job knowledge, memory effects, and training may affect a rater's ability to be accurate, other variables may influence a rater's motivation to perform accurate appraisals. The next section of the paper explains the proposed relationship between motivation and elaboration using the ELM framework.

\section{MOTIVATION FACTORS}

Managers may have low motivation to devote the necessary time and energy into the appraisal process to accurately assess subordinates since such efforts detract from more rewarding tasks, and providing low or average ratings can result in uncomfortable interactions with subordinates (Murphy, 1992; Spence \& Keeping, 2011). Yet, rater motivation can impact both the validity of the predictors and the reliability of performance ratings (Ispas, 2010). The potential importance of rater motivation has led some to call for more research on how rater motivation affects outcomes in the ratings process (De Kock, Lievens, \& Born, in press). The ELM provides a means of reviewing the effect of motivation on ratings accuracy in tandem with ability.

Based on the ELM, when motivation to rate accurately is low, raters should engage in low elaboration and use peripheral processing. Thus, they should be more likely than those using higher levels of elaboration to be influenced by peripheral cues and carry out less accurate performance evaluations. Conversely, when motivation to rate accurately is high, raters should engage in higher levels of elaboration via central processing resulting in a more deliberate examination of the dimensions of actual job performance and more accurate appraisals.

In a model of rater motivation, Harris (1994) concurs with this assumption, proposing that the unmotivated rater is less thorough in examining relevant performance information than the motivated rater and, consequently, is less accurate. Empirical evidence exists that raters with high motivation are more likely than raters with low motivation to seek additional information about performance and less likely to merely confirm first impressions (Higgins \& Bargh, 1987; Tetlock, 1983). In addition, Neuberg (1989) found that motivated raters in a simulated interview session asked more and better questions than unmotivated raters, while Cardy, Bernardin, Abbot, Senderak, and Taylor (1987) found that ratings were more accurate for highly motivated raters.

Harris (1994) proposes many variables that could affect rater motivation (e.g., self-efficacy, mood, organization's HR strategy, accountability, trust in system, etc.). While a number of variables may affect rater motivation to conduct accurate performance evaluations, rater accountability and company human resource strategy are utilized to illustrate the proposed relationship between motivation, level of elaboration, and rater accuracy.

\section{Accountability}

Accountability entails the social pressure a rater feels to fulfill expected evaluation obligations and justify his or her ratings to others (Wood \& Marshall, 2008; Schlenker, Britt, Pennington, Murphy, \& Doherty, 1994). Accountability may affect a rater's motivation to thoroughly examine actual 
performance-related information. The APA handbook on testing and assessment states that managers who are held accountable for their ratings "are much more likely to end up with valid and useful ratings than [those who] clearly do not care about the quality of rating data" (Murphy \& Deckert, 2013, p. 624). Some studies in both the public and private sectors indicate that managers who are accountable to their bosses are more accurate in their evaluations of subordinate performance than managers not held accountable (Bernardin, Thomason, Buckley, \& Kane, 2016; Curtis, Harvey, \& Ravden, 2005; Mero, Guidice, \& Brownlee, 2007; Park, 2014; Roch, Ayman, Newhouse, \& Harris, 2005). Yet, one recent study found that only $44 \%$ of organizations actually hold raters accountable (Gorman, Meriac, Roch, Ray, \& Gamble, 2017)

Two factors can be seen to increase a rater's accountability to his or her superior: (1) the degree to which the rater believes the superior will review the ratings, and (2) the likelihood the superior will challenge the rater's appraisal (Harris, 1994). If the occurrence of these events are perceived as highly likely, Harris (1994) believes the rater will engage in high levels of "performance appraisal information processing and make accurate ratings" (p. 745). Consequently, it seems reasonable that high accountability to superiors will create a situation of high elaboration where a rater would be more likely to engage in a thoughtful examination of the dimensions of actual job performance. A situation of low accountability would create conditions of lower elaboration and a greater likelihood that a rater would be influenced by peripheral cues and thus commit more rating inaccuracies than a rater engaged in higher elaboration.

Proposition 5: Raters who feel lower accountability to superiors will engage in lower elaboration than raters experiencing higher accountability, and thus are more likely to be influenced by peripheral cues in the ratings process and experience lower accuracy.

\section{Human Resource Strategy}

There is recognition among HR researchers and practitioners of the need to link business strategy and HR practices in organizations. Human resource practices need to complement the overall business strategy to help ensure successful strategy implementation (Buller \& McEvoy, 2012; Guest, 2011; Wright, Dunford, \& Snell, 2001). In an analysis of the business strategy and HR practices of organizations (Sonnenfeld \& Peiperl, 1988), one way organizations were differentiated was by their emphasis on internal staffing practices, with some organizations placing strong emphasis on promoting from within while others fill positions through external sources. Performance appraisals are an important element in the successful implementation of internal staffing programs. Organizations that promote from within place high emphasis on developmental programs, and the administrative and feedback functions of performance appraisals are a key part of such programs (Dorsey \& Mueller-Hanson, 2017; Hall, 1984). Consequently, organizations that stress internal staffing practices should place an emphasis on performance appraisals such that the process will be monitored more closely and rewarded more highly than in organizations that staff from external sources. Raters in such organizations should feel motivation to examine information and evidence related to actual job performance and thus engage in high elaboration. Raters in organizations that do not place a high emphasis on internal hiring should engage in lower levels of elaboration and thus be more influenced by peripheral cues and more subject to inaccuracies in their assessment of employee performance.

Proposition 6: Raters in organizations with a weak emphasis on internal staffing will engage in lower elaboration than raters in organizations with a stronger emphasis on internal staffing, and thus are more likely to be influenced by peripheral cues in the ratings process and experience lower accuracy.

In summary, based on the ELM a rater's ability and motivation should influence the level of elaboration used to consider the dimensions of an employee's actual job performance. To the degree that raters have both ability and motivation, they should engage in higher levels of elaboration and utilize central processing. Conversely, to the degree that ability and/or motivation are low, raters should engage 
in lower levels of elaboration using peripheral processing and be more susceptible to rating inaccuracies caused by factors and traits that are not relevant to actual job performance.

Research results have been presented and several ability and motivational factors have been discussed in the context of the ELM, emphasizing the relationship between the degree of elaboration and performance appraisal inaccuracy. In the next section, the ELM framework will be used to discuss variables known to influence ratings but that are unrelated to actual job performance (i.e., peripheral cues).

\section{NONPERFORMANCE FACTORS IN PERFORMANCE APPRAISALS}

The ELM suggests that raters using peripheral processing are more likely to make performance assessments of ratees by using simple environmental or peripheral cues than raters using central processing. Peripheral cues will most likely affect performance evaluations when either rater ability or motivation is low. Although many potential peripheral cues exist, in this section of the paper propositions related to the effect of two peripheral cues (attractiveness and prior expectations) on performance ratings will be used to illustrate the explanatory ability of the ELM regarding rating inaccuracies. Since these variables tend to not be related to actual dimensions of job performance, they are viewed as peripheral cues.

\section{Attractiveness}

One peripheral cue shown in research to relate to performance ratings is attractiveness of the employee. A bias for attractiveness has been reported in a number of studies on various job-related outcomes in a variety of business contexts (Jackson, 1992; Morrow, 1990; Stone, Stone, \& Dipboye, 1992). Attractiveness tends to benefit workers in performance ratings (Langlois, Kalakanis, Rubenstein, Larson, Hallam, \& Smoot, 2000), promotion (Morrow, McElroy, Stamper, \& Wilson, 1990) and compensation decisions (Hosoda, Stone-Romero, \& Coats, 2003). Hamermesh and Biddle (1994) found that attractive workers earn a compensation premium of 10 to 15 percent above that of workers with average attractiveness. In an experimental study where students were paid to solve computer mazes, workers deemed more physically attractive were judged as more capable even though attraction did not affect actual performance (Mobius \& Rosenblat, 2006). This is in line with findings from two metaanalysis reviews which show that people viewed as attractive are more likely to receive higher performance appraisals, among other job related outcomes, than their less attractive co-workers (Hosoda et al., 2003; Langlois et al., 2000).

Based on the research results discussed above and given that attractiveness tends to not be related to actual performance, the ELM would predict that attractiveness will have more of an effect on performance appraisal ratings under conditions of low rather than high elaboration.

Proposition 7: Raters engaged in lower levels of elaboration will be more influenced by employee attractiveness than raters engaged in higher levels of elaboration.

\section{Prior Expectations}

Another peripheral cue is that of prior expectations of an employee's performance. Prior expectations can cause contrast effects leading to inaccurate ratings. Contrast effects can occur in the context of an employee being evaluated against his or her own prior performance. The effect has been found to either artificially raise or lower performance ratings (Kane et al., 1995). Some research shows that when a rater has knowledge of past performance, the appraisal is biased away from the level of past performance (Murphy, Balzer, Lockhart, \& Eisenman, 1985). In examining the effect of having actually participated in the previous performance rating, Sumer and Knight (1996) found that raters who previously assessed an individual's performance tend to rate a later performance in the opposite direction from the first rating.

Other research indicates that when behavior is not consistent with prior expectations, ratings suffer (Mount \& Thompson, 1987). Hogan (1987) states that disconfirming a supervisor's expectations in either 
direction hurts a subordinate, finding that when actual performance disappoints or exceeds expectations, ratings are lower than performance indicates they should be. Another study finds that an actual low level of performance is rated lower when an individual's previous performance was high rather than low (Gaugler \& Rudolph, 1992).

Based on the above-mentioned findings and given that prior expectations can bias subsequent performance ratings even when such ratings are not indicative of the latter performance, the ELM would predict that prior expectations will have more of an effect on performance appraisal ratings under conditions of low rather than high elaboration.

Proposition 8: Raters engaged in lower levels of elaboration will be more influenced by prior expectations and be more likely to experience contrast effects than raters engaged in higher levels of elaboration.

To summarize, the Elaboration Likelihood Model can be useful for predicting when variables unrelated to actual performance will influence a rater's judgment. The factors of attractiveness and prior performance expectations were used to illustrate how performance ratings are affected when raters operate under conditions of low elaboration (i.e., peripheral processing) when either motivation or ability to rate accurately are low.

\section{CONCLUSIONS AND IMPLICATIONS FOR FUTURE RESEARCH}

Utilizing the Elaboration Likelihood Model to explain the occurrence of unintentional inaccuracies in the performance appraisal process can increase understanding of how and when such errors occur. The ELM illustrates the importance of ability and motivation in explaining how variables not related to performance can affect rater accuracy. Such a theoretical combination of ability and motivation has been lacking in appraisal research (DeNisi \& Pritchard, 2006).

The ability of the ELM to explain the occurrence of bias in the performance appraisal process needs to be tested through research. Research involving the ELM has typically been conducted in experimental studies. This enables testing of hypotheses related to high and low levels of elaboration through the manipulation of ability and motivation. Although the ELM proposes that ability and motivation are both needed for the condition of high elaboration, a typical experiment manipulates only one of the variables. The assumption is made that the remaining variable is constant among the participants.

In a typical study, three variables are manipulated: the quality of issue-relevant information, a peripheral cue, and either ability or motivation (see Petty \& Cacioppo, 1986). For example, participants asked to rate the performance of an individual could be given information indicating either above-average or below-average performance (i.e., issue-relevant information). To manipulate the peripheral cue, participants could be provided a picture of the employee along with the job performance information, with half of the participants receiving a picture showing an employee with high attractiveness and the other half receiving a picture showing low attractiveness. The ability of the rater could be manipulated by supplying half of the participants with detailed job information regarding tasks, responsibilities, working conditions, expectations, etc., while the other half could be given merely the job title and information about the company. The high and low ability groups would create conditions of high and low elaboration.

Based on typical experiments utilizing the ELM framework, the expected results for such an experimental study would be two main effects for the issue-relevant information (i.e., above-average performance vs. below-average performance) and peripheral cue (i.e., high attractiveness vs. low attractiveness). In addition, two interactions would be expected between the variables representing the level of elaboration (i.e., ability), issue-relevant information, and peripheral cue. In the high elaboration condition (high ability), expectations would be that participant ratings would be more affected by the message content of actual performance information and less affected by the peripheral cue of attractiveness than participant ratings in the low elaboration condition (low ability). Conversely, in the low elaboration condition, expectations would be that participant ratings would be more affected by 
attractiveness and less affected by performance-related information than participant ratings in the high elaboration condition, thus resulting in less accurate ratings.

Correlational field studies could also be employed to test the ELM. While a laboratory setting is typically utilized to test the model, the ELM could be used to examine the moderating effect of motivational and ability variables in the relationship between peripheral cues (e.g., employee attractiveness) and employee performance ratings.

The ELM may be a useful tool for examining how and when performance-relevant information or peripheral cues may influence the ratings process. The ELM also has practical application for improving the performance ratings process through increasing elaboration which should result in more valid assessments of worker performance. To increase elaboration and the likelihood that performance-related information is used in assessing worker performance, organizations should consider factors that increase both rater ability and motivation. For example, to improve ability organizations could increase the job knowledge of raters, ensuring that they understand key criteria for successful job performance. Memory decay could also be minimized by conducting more than one appraisal per year and recording critical incidents related to good and poor performance throughout the year. Research has shown that instructing raters through techniques such as frame-of-reference training can improve ratings accuracy (Moser et al., 2018; Roch et al., 2012). Holding raters accountable to supervisors for their ratings and increasing organizational dependence on performance appraisal scores are some tactics organizations can take to increase motivation of raters (Murphy \& Deckert, 2013).

In conclusion, the Elaboration Likelihood Model holds promise for research on performance appraisal accuracy by providing a framework for explaining how factors unrelated to job performance may affect rating decisions. By increasing elaboration appraisals should be based more on actual performance data and employee behaviors, with raters' judgments less likely to be affected by factors unrelated to performance. 


\section{REFERENCES}

Arvey, R. D., \& Murphy, K. R. (1998). Performance evaluation in work settings. Annual Review of Psychology, 49, 141-168. https://doi.org/10.1146/annurev.psych.49.1.141

Bernardin, H. J., Orban, J. A., \& Carlyle, J. J. (1981). Performance rating as a function of trust in appraisal and rater individual differences. Proceedings of the Academy of Management Meetings, 311-315. https://doi.org/10.5465/ambpp.1981.4977034

Bernardin, H. J., Thomason, S., Buckley, M. R., \& Kane, J. S. (2016). Rater rating-level bias and accuracy in performance appraisals: The impact of rater personality, performance management competence, and rater accountability. Human Resource Management, 55(2), 321-340. https://doi.org/10.1002/hrm.21678

Biron, M., Farndale, E., \& Paauwe, J. (2011). Performance management effectiveness: Lessons from world-leading firms. The International Journal of Human Resource Management, 22(6), 12941311. https://doi.org/10.1080/09585192.2011.559100

Brown, T. C., O’Kane, P., Mazumdar, B., \& McCracken, M. (2019). Performance management: A scoping review of the literature and an agenda for future research. Human Resource Development Review, 18(1), 47-82. https://doi.org/10.1177/1534484318798533

Buller, P. F., \& McEvoy, G. M. (2012). Strategy, human resource management and performance: Sharpening line of sight. Human Resource Management Review, 22(1), 43-56. https://doi.org/10.1016/j.hrmr.2011.11.002

Cardy, R. L., Bernardin, H. J., Abbot, J. G., Senderak, M. P., \& Taylor, K. (1987). The effects of individual performance schemata and dimension familiarization on rating accuracy. Journal of Occupational Psychology, 60(3), 197-205. https://doi.org/10.1111/j.2044-8325.1987.tb00253.x

Curtis, A. B., Harvey, R. D., \& Ravden, D. (2005). Sources of political distortions in performance appraisals: Appraisal purpose and rater accountability. Group \& Organization Management, 30(1), 42-60. https://doi.org/10.1177/1059601104267666

De Kock, F. S., Lievens, F., \& Born, M. P. (in press). The profile of the 'Good Judge' in HRM: A systematic review and agenda for future research. Human Resource Management Review. https://doi.org/10.1016/j.hrmr.2018.09.003

Dello Russo, S., Miraglia, M., \& Borgogni, L. (2017). Reducing organizational politics in performance appraisal: The role of coaching leaders for age-diverse employees. Human Resource Management, 56(5), 769-783. https://doi.org/10.1002/hrm.21799

DeNisi, A. S., \& Murphy, K. R. (2017). Performance appraisal and performance management: 100 years of progress? Journal of Applied Psychology, 102(3), 421-433. http://dx.doi.org/10.1037/ap10000085

DeNisi, A. S., \& Peters, L. H. (1996). Organization of information in memory and the performance appraisal process: Evidence from the field. Journal of Applied Psychology, 81(6), 717-737. http://dx.doi.org/10.1037/0021-9010.81.6.717

DeNisi, A. S., \& Pritchard, R. D. (2006). Performance appraisal, performance management and improving individual performance: A motivational framework. Management and Organization Review, 2(2), 253-277. https://doi.org/10.1111/j.1740-8784.2006.00042

Dorsey, D., \& Mueller-Hansen, R. (2017). Performance management that makes a difference: An evidenced-based approach (Science-to-Practice Guidelines). Alexandria, VA: SHRM.

Foti, R. J., \& Lord, R. G. (1987). Prototypes and scripts: The effects of alternative methods of processing information on rating accuracy. Organizational Behavior and Human Decision Processes, 39(3), 318-340. https://doi.org/10.1016/0749-5978(87)90027-6

Frank-Major, S. L., \& Foti, R. J. (1985). Accuracy in performance appraisals: A comparison of two rater cognitive process models (TR-ONR-1). College Station, Texas A\&M University, Dept. of

Management and Dept. of Psychology. Retrieved from https://apps.dtic.mil/dtic/tr/fulltext/u2/a162585.pdf

74 Journal of Management Policy and Practice Vol. 20(4) 2019 
Gaugler, B. B., \& Rudolph, A. S. (1992). The influence of assessee performance variation on assessors' judgments. Personnel Psychology, 45(1), 77-98. https://doi.org/10.1111/j.17446570.1992.tb00845.x

Goldberg, E. L. (2014, August). Performance management gets social. HR Magazine, 59(8), 34-38.

Gorman, C. A., Meriac, J. P., Roch, S. G., Ray, J. L., \& Gamble, J. S. (2017). An exploratory study of current performance management practices: Human resource executives' perspectives. International Journal of Selection and Assessment, 25(2), 193-202. https://doi.org/10.1111/ijsa.12172

Gorman, C. A., \& Rentsch, J. R. (2009). Evaluating frame-of-reference rater training effectiveness using performance schema accuracy. Journal of Applied Psychology, 94, 1336-1344. https://doi.org/10.1037/a0016476

Guest, D. E. (2011). Human resource management and performance: Still searching for some answers. Human Resource Management Journal, 21(1), 3-13. https://doi.org/10.1111/j.17488583.2010.00164.x

Hall, D. (1984). Human resource development and organizational effectiveness. In C. Fombrun, N. Tichy, and M. DeVanna (Eds.), Strategic human resource management. New York: Wiley.

Hamermesh, D. S., \& Biddle, J. E. (1994). Beauty and the labor market. American Economic Review, 84(5), 1174-1194. Retrieved from http://www.jstor.org/stable/2117767

Harris, M. M. (1994). Rater motivation in the performance appraisal context: A theoretical framework. Journal of Management, 20(4), 735-756. https://doi.org/10.1177/014920639402000403

Heneman, R. L., \& Wexley, K. N. (1983). The effects of time delay in rating and amount of information observed on performance rating accuracy. Academy of Management Journal, 26(4), 677-686. https://doi.org/10.5465/255915

Higgins, E. T., \& Bargh, J. A. (1987). Social cognition and social perception. Annual Review of Psychology, 38, 369-425. https://doi.org/10.1146/annurev.ps.38.020187.002101

Hogan, E. A. (1987). Effects of prior expectations on performance ratings: A longitudinal study. Academy of Management Journal, 30(2), 354-368. https://doi.org/10.5465/256279

Hosoda, M., Stone-Romero, E. F., \& Coats, G. (2003). The effects of physical attractiveness on jobrelated outcomes: A meta-analysis of experimental studies. Personnel Psychology, 56(2), 431462. https://doi.org/10.1111/j.1744-6570.2003.tb00157.x

Ilgen, D. R., Barnes-Farrell, J. L., \& McKellin, D. B. (1993). Performance appraisal process research in the 1980s: What has it contributed to appraisals in use? Organizational Behavior and Human Decision Processes, 54(3), 321-368. https://doi.org/10.1006/obhd.1993.1015

Ispas, D. (2010). The role of rater motivation in personnel selection validation studies (Unpublished doctoral dissertation). University of South Florida, Tampa FL. Retrieved from http://scholarcommons.usf.edu/etd/3473

Jackson, L. A. (1992). Physical appearance and gender: Sociobiological and sociocultural perspectives. Albany, NY: State University of New York Press.

Kane, J. S, Bernardin, H. J., \& Wiatrowski, M. (1995). Performance appraisal. In N. Brewer \& C. Wilson (Eds.), Psychology and policing (pp. 257-290). Hillsdale, NJ: Erlbaum.

Kozlowski, S. W., \& Kirsch, M. P. (1987). The systematic distortion hypothesis, halo, and accuracy: An individual-level analysis. Journal of Applied Psychology, 72(2), 252-261. http://dx.doi.org/10.1037/0021-9010.72.2.252

Kozlowski, S. W., Kirsch, M. P., \& Chao, G. T. (1986). Job knowledge, ratee familiarity, conceptual similarity and halo error: An exploration. Journal of Applied Psychology, 71(1), 45-49. http://dx.doi.org/10.1037/0021-9010.71.1.45

Langlois, J. H., Kalakanis, L., Rubenstein, A. J., Larson, A., Hallam, M., \& Smoot, M. (2000). Maxims or myths of beauty? A meta-analytic and theoretical review. Psychological Bulletin, 126(3), 390423. https://doi.org/10.1037/0033-2909.126.3.390 
Longenecker, C. O., Sims, H. P., \& Gioia, D. A. (1987). Behind the mask: The politics of employee appraisal. The Academy of Management Executive, 1(3), 183-193.

https://doi.org/10.5465/ame.1987.4275731

Mero, N. P., Guidice, R. M., \& Brownlee, A. L. (2007). Accountability in a performance appraisal context: The effect of audience and form of accounting on rater response and behavior. Journal of Management, 33(2), 223-252. https://doi.org/10.1177/0149206306297633

Mobius, M. M., \& Rosenblat, T. S. (2006). Why beauty matters. American Economic Review, 96(1), $222-$ 235. https://doi.org/10.1257/000282806776157515

Morrow, P. C. (1990). Physical attractiveness and selection decision making. Journal of Management, 16(1), 45-60. https://doi.org/10.1177/014920639001600104

Morrow, P. C., McElroy, J. C., Stamper, B. G., \& Wilson, M. A. (1990). The effects of physical attractiveness and other demographic characteristics on promotion decisions. Journal of Management, 16(4), 723-736. https://doi.org/10.1177/014920639001600405

Moser, K., Kemter, V., Wachsmann, K., Köver, N. Z. \& Soucek, R. (2018). Evaluating rater training with double-pretest one-posttest designs: An analysis of testing effects and the moderating role of rater self-efficacy. The International Journal of Human Resource Management, 29(18), 2609-2631. https://doi.org/10.1080/09585192.2016.1254102

Mount, M. K., \& Thompson, D. E. (1987). Cognitive categorization and quality of performance ratings. Journal of Applied Psychology, 72(2), 240-246. http://dx.doi.org/10.1037/0021-9010.72.2.240

Murphy, K. J. (1992). Performance measurement and appraisal: Motivating managers to identify and reward performance. In W. J. Bruns (Ed.), Performance measurement, evaluation, and incentives (pp. 37-62). Boston: Harvard Business School.

Murphy, K. R., \& Balzer, W. K. (1986). Systematic distortions in memory-based behavior ratings and performance evaluations: Consequences for rating accuracy. Journal of Applied Psychology, 71(1), 39-44. http://dx.doi.org/10.1037/0021-9010.71.1.39

Murphy, K. R., Balzer, W. K., Lockhart, M. C., \& Eisenman, E. J. (1985). Effects of previous performance on evaluations of present performance. Journal of Applied Psychology, 70(1), 72-84. http://dx.doi.org/10.1037/0021-9010.70.1.72

Murphy, K. R., \& Cleveland, J. N. (1995). Understanding Performance Appraisal: Social, Organizational, and Goal-Based Perspectives. Thousand Oaks, CA: Sage Publications.

Murphy, K. R., \& Deckert, P. J. (2013). Performance appraisal. In K. F. Geisinger, B. A. Bracken, J. F. Carlson, J. C. Hansen, N. R. Kuncel, S. P. Reise, \& M. C. Rodriguez (Eds.), APA handbook of testing and assessment in psychology, Vol. 1. Test theory and testing and assessment in industrial and organizational psychology (pp. 611-627). Washington, DC, US: American Psychological Association. http://dx.doi.org/10.1037/14047-000

Neuberg, S. L. (1989). The goal of forming accurate impressions during social interactions: Attenuating the impact of negative expectancies. Journal of Personality and Social Psychology, 56(3), 374386. http://dx.doi.org/10.1037/0022-3514.56.3.374

Park, S. (2014). Motivation of public managers as raters in performance appraisal: Developing a model of rater motivation. Public Personnel Management, 43(4), 387-414. https://doi.org/10.1177/0091026014530675

Petty, R. E., \& Cacioppo, J. T. (1986). The elaboration likelihood model of persuasion. In L. Berkowitz (Ed.), Advances in experimental social psychology (pp. 123-205). Orlando, FL: Academic Press. https://doi.org/10.1016/S0065-2601(08)60214-2

Pichler, S. (2012). The social context of performance appraisal and appraisal reactions: A meta-analysis. Human Resource Management, 51(5), 709-732. https://doi.org/10.1002/hrm.21499

Pulakos, E. D. (2004). A Roadmap for Developing, Implementing, and Evaluating Performance Management Systems. Alexandria, VA: SHRM Foundation.

Pulakos, E. D., Mueller-Hanson, R. A., O’Leary, R. S., \& Meyrowitz, M. M. (2012). Building a highperformance culture: A fresh look at performance management (Effective Practices Guidelines). Alexandria, VA: SHRM Foundation.

76 Journal of Management Policy and Practice Vol. 20(4) 2019 
Roch, S. G., Ayman, R., Newhouse, N., \& Harris, M. (2005). Effect of identifiability, rating audience, and conscientiousness on rating level. International Journal of Selection and Assessment, 13(1), 53 62. https://doi.org/10.1111/j.0965-075X.2005.00299.x

Roch, S. G., Woehr, D. J., Mishra, V., \& Kieszczynska, U. (2012). Rater training revisited: An updated meta-analytic review of frame-of-reference training. Journal of Occupational and Organizational Psychology, 85(2), 370-395. https://doi.org/10.1111/j.2044-8325.2011.02045.x

Sanchez, J. I., \& De La Torre, P. (1996). A second look at the relationship between rating and behavioral accuracy in performance appraisal. Journal of Applied Psychology, 81(1), 3-10. http://dx.doi.org/10.1037/0021-9010.81.1.3

Schlenker, B. R., Britt, T. W., Pennington, J., Murphy, R., \& Doherty, K. (1994). The triangle model of responsibility. Psychological Review, 101(4), 632-652. http://dx.doi.org/10.1037/0033295X.101.4.632

Sonnenfeld, J. A., \& Peiperl, M. A. (1988). Staffing policy as a strategic response: A typology of career systems. Academy of Management Review, 13(4), 588-600. https://doi.org/10.5465/amr.1988.4307437

Spence, J. R., \& Keeping, L. (2011). Conscious rating distortion in performance appraisal: A review, commentary, and proposed framework for research. Human Resource Management Review, 21(2), 85-95. https://doi.org/10.1016/j.hrmr.2010.09.013

Steiner, D. D., \& Rain, J. S. (1989). Immediate and delayed primacy and recency effects in performance evaluation. Journal of Applied Psychology, 74(1), 136-142. http://dx.doi.org/10.1037/00219010.74.1.136

Stone, E. F., Stone, D. L., \& Dipboye, R. L. (1992). Stigmas in organizations: Race, handicaps, and physical unattractiveness. In K. Kelley (Ed.), Issues, theory, and research in industrial and organizational psychology (pp. 385-457). Oxford, U.K.: North-Holland. https://doi.org/10.1016/S0166-4115(08)62608-4

Sumer, H. C., \& Knight, P. A. (1996). Assimilation and contrast effects in performance ratings: Effects of rating the previous performance on rating subsequent performance. Journal of Applied Psychology, 81(4), 436-442. http://dx.doi.org/10.1037/0021-9010.81.4.436

Tetlock, P. E. (1983). Accountability and the perseverance of first impressions. Social Psychology Quarterly, 46(4), 285-292. https://doi.org/10.2307/3033716

Woehr, D. J., \& Huffcutt, A. I. (1994). Rater training for performance appraisal: A quantitative review. Journal of Occupational and Organizational Psychology, 67(3), 189-205. https://doi.org/10.1111/j.2044-8325.1994.tb00562.x

Wood, R. E., \& Marshall, V. (2008). Accuracy and effectiveness in appraisal outcomes: The influence of self-efficacy, personal factors and organisational variables. Human Resource Management Journal, 18(3), 295-313. https://doi.org/10.1111/j.1748-8583.2008.00067.x

Wright, P. M., Dunford, B. B., \& Snell, S. A. (2001). Human resources and the resource based view of the firm. Journal of Management, 27(6), 701-721. https://doi.org/10.1177/014920630102700607 